\title{
The age of honey bee larvae at grafting can affect survival during larval tests
}

\author{
Martin Staron' ${ }^{1}$, Rastislav Sabo ${ }^{2}$, Dana Staroňová', Lucia Sabová2 ${ }^{2}$, Hossam F. Abou-Shaara ${ }^{3 *}$ \\ ${ }^{1}$ Research Institute for Animal Production Nitra, Institute of Apiculture Liptovský Hrádok, Slovakia \\ ${ }^{2}$ University of Veterinary Medicine and Pharmacy in Košice, Komenského 73, 04181 Košice, Slovakia \\ ${ }^{3}$ Department of Plant Protection, Faculty of Agriculture, Damanhour University, Damanhour, 22516, Egypt \\ *Corresponding author, E-mail: hossam.farag@agr.dmu.edu.eg
}

\begin{abstract}
Honey bee larvae have been used in many experiments to assess the hazards of the environmental pollutants, including pesticides. Most studies have used one-day-old larvae to perform the experiments. This study aims to investigate the effects of larval age at grafting on survival during laboratory tests. Larvae grafted at different ages (one, three, and four days old) were compared in regard to their survival under the same laboratory conditions until hatching of adults. Our results showed that the main reason of death of larvae or pupae prior to the completion of the development was due to larval age at grafting. The grafted three-day-old larvae had better survival and were practically easier to use than the other two ages, hence the option of using larvae at this age during larval tests is supported.
\end{abstract}

Key words: honey bees, laboratory conditions, larvae,

Abbreviations: ESM, estimated survival mean.

\section{Introduction}

Honey bees, Apis mellifera, have been used in many studies as a model insect (Elekonich, Roberts 2005) and can be used to monitor the negative effects of chemicals, and as bioindicators to the environmental pollutants (Conti, Botrè 2001; Balayiannis, Balayiannis 2008; Zhelyazkova 2012). Foraging behaviour is the main link between bee colonies and the ambient environment (Abou-Shaara 2014). Forager bees can fligh long distances to gather nectar, pollen, propolis or water (Visscher et al. 1996). These sources can be contaminated with many pollutants including pesticides and heavy metals (Johnson 2015; Mullin et al. 2010).

Honey bee larvae are reared in cells inside the wax combs and can be potentially exposed to environmental pollutants via contaminated diet. Therefore, honey bee larvae can be easily used in laboratory tests (in vitro larval tests) to evaluate the toxicity of xenobiotics or effects of other factors, e.g. temperature (Abou-Shaara et al. 2017). Mortality of larvae and number of hatched adults are generally the main parameters to evaluate the effects of studied factors (OECD 2013), but also the characteristics of emerged adults, for example body morphology (Ken et al. 2005), learning ability or dance performance (Tautz et al. 2003) have been studied. Factors that can affect survival of larvae under laboratory conditions include feeding (Aupinel et al. 2005) and rearing environment (Crailsheim et al. 2013). However, the effect of larval age at grafting on survival has not been widely investigated yet. According to OECD 237 (2013) and OECD recommendations for repeated exposure (2016), one day old larvae have been suggested for use in larval tests.

The aim of the present study was to investigate whether larval age at grafting can affect the subsequent survival and development. Survival of synchronized larvae at three different ages during the grafting phase of bioassay until hatching of adults were compared under the same laboratory conditions.

\section{Materials and methods}

\section{Colonies and queens}

Honey bee larvae were obtained from an apiary in Liptovský Hrádok (Slovakia), which is located in an extensively used agricultural mountain range. During summer 2018, the larvae originated from three 1-year-old honey bee nonsister queens (Apis mellifera carnica) that were confined in their own colony in an exclusion cage until grafting to obtain larvae in different ages (OECD 2013).

\section{Rearing of larvae}

The bee larvae were in vitro reared in a hermetic desiccator until day 8 (temperature $34.5 \pm 0.5^{\circ} \mathrm{C}$ and relative humidity $95 \pm 5 \%)$. Then the larvae were transferred into a hermetic container until hatching (temperature $34.5 \pm 0.5{ }^{\circ} \mathrm{C}$ and relative humidity $80 \pm 5 \%$ until day 15 , and $50 \pm 5 \%$ until hatching) according OECD (2016) recommendations for repeated exposure. The larvae were grafted in three 48 -well 
plates. Each plate contained 16 larvae from each queen in two replications ( 1 replication $=8$ larvae) with a total of 48 larvae obtained from the three queens. The first plate contained one day old larvae (group A), the second plate contained 3-day-old larvae (group B), and the third plate contained 4-day-old larvae (group C). Larvae synchronized to specific age were grafted at the same time (older larvae were kept in the hive until grafting), grafting was performed by one person. Larval food was composed of three diets (depending on their age), adapted to the needs of the larvae at different stages of development, and followed OECD (2016). Development of larvae and pupae was observed and any dead larvae or pupae were recorded with exception of emergence of adult bees, which occurred on day 20 .

\section{Statistical analysis}

Multi-comparison based on the Bonferroni test was utilized to determine significance of mortality data among the observed groups. Also, the Kaplan-Meier test was used to compare survival curves of each group, and the estimated survival means (ESM) were calculated. Moreover, the effect of queens as a source of larvae on survival was analysed. Significant differences $(p \leq 0.05)$ between the groups were detected using the Log Rank Mantel-Cox test. The analysis was performed using SPSS v. 16 (Released 2007, SPSS for Windows, Version 16.0. Chicago, USA).

\section{Results and discussion}

Higher cumulative mortality in group $\mathrm{C}$ compared to group A on day 6 was recorded. Group B had no mortality up to day 8. On day 7 (Fig. 1), the preferred day of mortality evaluation according to OECD (2016) reccommendations for repeated exposure, the cumulative mortality of group $B$ was still zero, and significant mortality was recorded in group A $(10.41 \pm 6.2 \%, p=0.33)$ and group C (25 \pm $6.2 \%, p=0.003)$ compared to group B. The mortality on day 15 and 20 were used for evaluation of the experiments according to the OECD (2016) methodology. Observations were recorded up to day 20 as hatching of all adult bees from the surviving larvae occurred on that day. On day 15 , cumulative mortality reached $8.33 \pm 10.2 \%$ in group B, and $10.41 \pm 5.1 \%$ by $2.1 \pm 5.6 \%$ in group A, without significant difference $(p=1)$ between groups. Group C showed the highest level of cumulative mortality $(35.41 \pm 12.3 \%)$, which was significantly higher $(p=0.001)$ than for group B $(27.1 \pm 5.6 \%)$. On day 20 , the cumulative mortality was $12.5 \pm 7.9 \%, 16.66 \pm 15.1 \%$, and $43.75 \pm 13.1 \%$ for group A, group B, and group C, respectively. Group C had higher mortality rates than the two other groups.

The survival analysis (Fig. 2) showed significantly greater decline (Mantel-Cox 15.922, $p=0.000$ ) in the survival of immature stages of group C (4-day-old larvae) than for the other two groups. No significant differences were found in this analysis between group A and B (Mantel-Cox 0.232, p
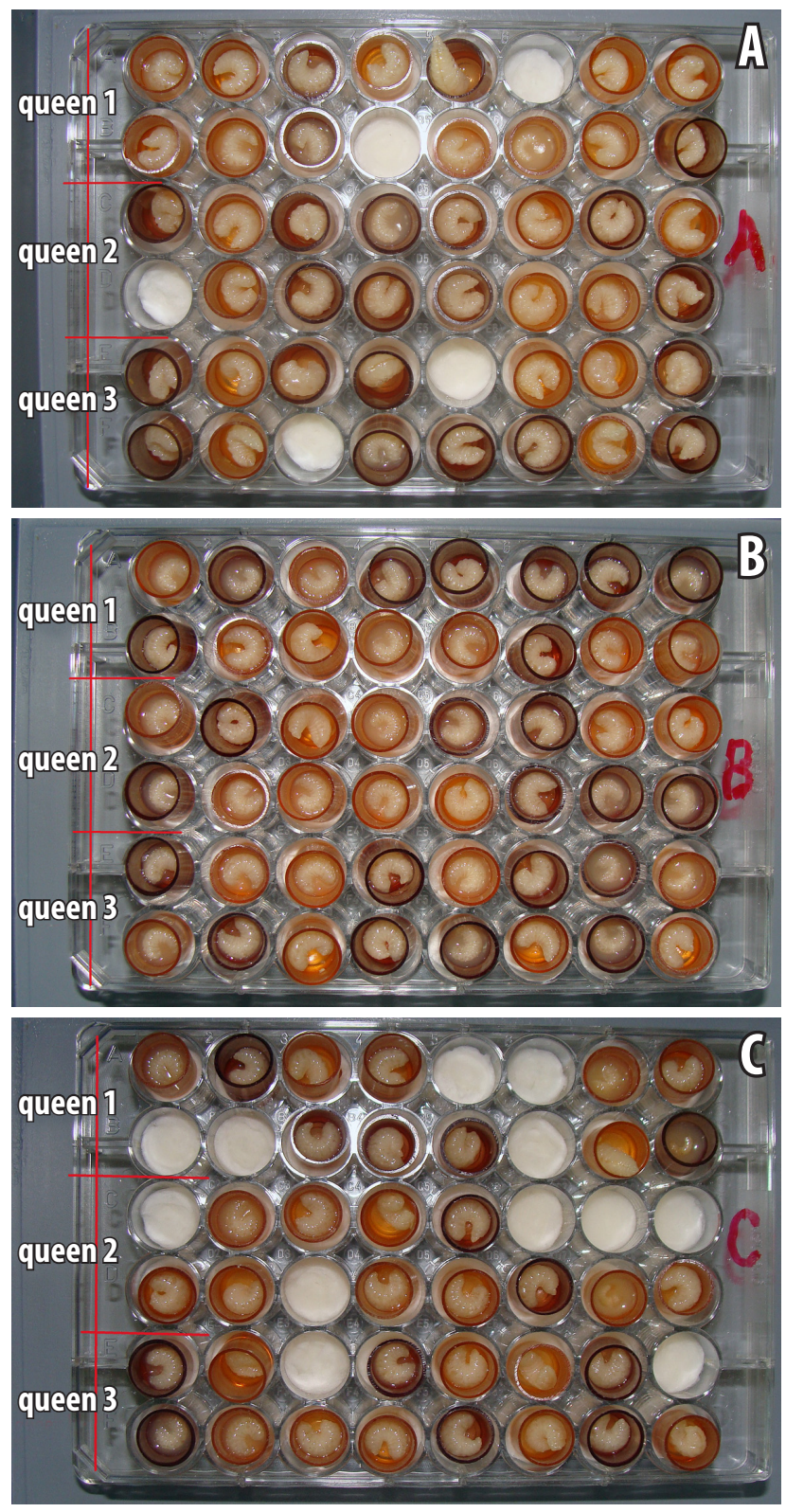

Fig. 1. Mortality of larvae on day 7. For group A (1-day-old larvae, A); group B (3-day-old larvae, B); group C (4-day-old larvae). In respective treatments, 5, 0, and 12 larvae have died.

$=0.63)$, while significant differences were found between group C and A (Mantel-Cox 10.330, $p=0.001$ ) and group C and B (Mantel-Cox 9.503, $p=0.002$ ). The ESM was $18.37 \pm$ $0.68,19.16 \pm 0.33$, and $15.43 \pm 0.90$ days for group $A, B$, and $\mathrm{C}$, respectively. It is evident that 3-day-old larvae showed better survival than the other two tested ages during the experimental period. In group A, higher mortality was observed during the first days after grafting in comparison to group B. This may be a result of damage caused to very small one-day-old larvae during grafting. The mortality of group A kept decreasing but on day 17 became identical to group B. Grafting of 3-day-old larvae was technically 


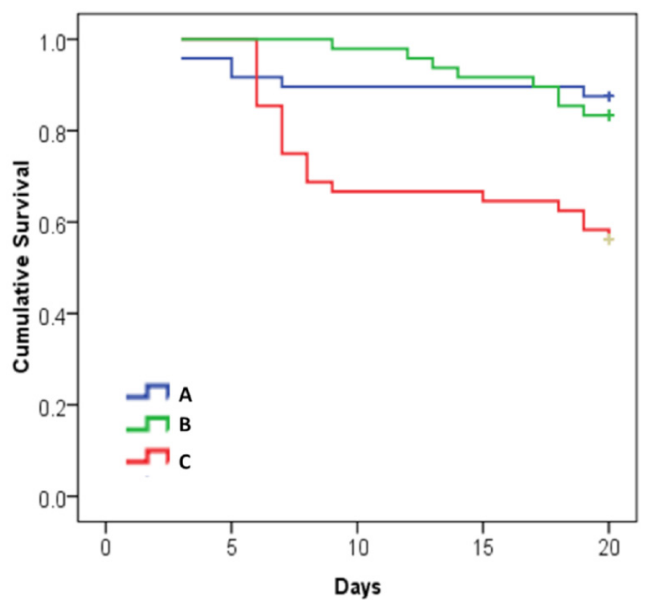

Fig. 2. Cumulative survival of larvae and pupae over 20 days. A, group A, 1-day-old larvae; B, group B, 3-day-old larvae; C, group C, 4-day-old larvae.

simple and easily conducted while grafting of 4-day-old larvae was very difficult. Four-day-old larvae are large and damages to their bodies can easily occur during grafting, and this may explain the subsequent higher mortality observed in our test.
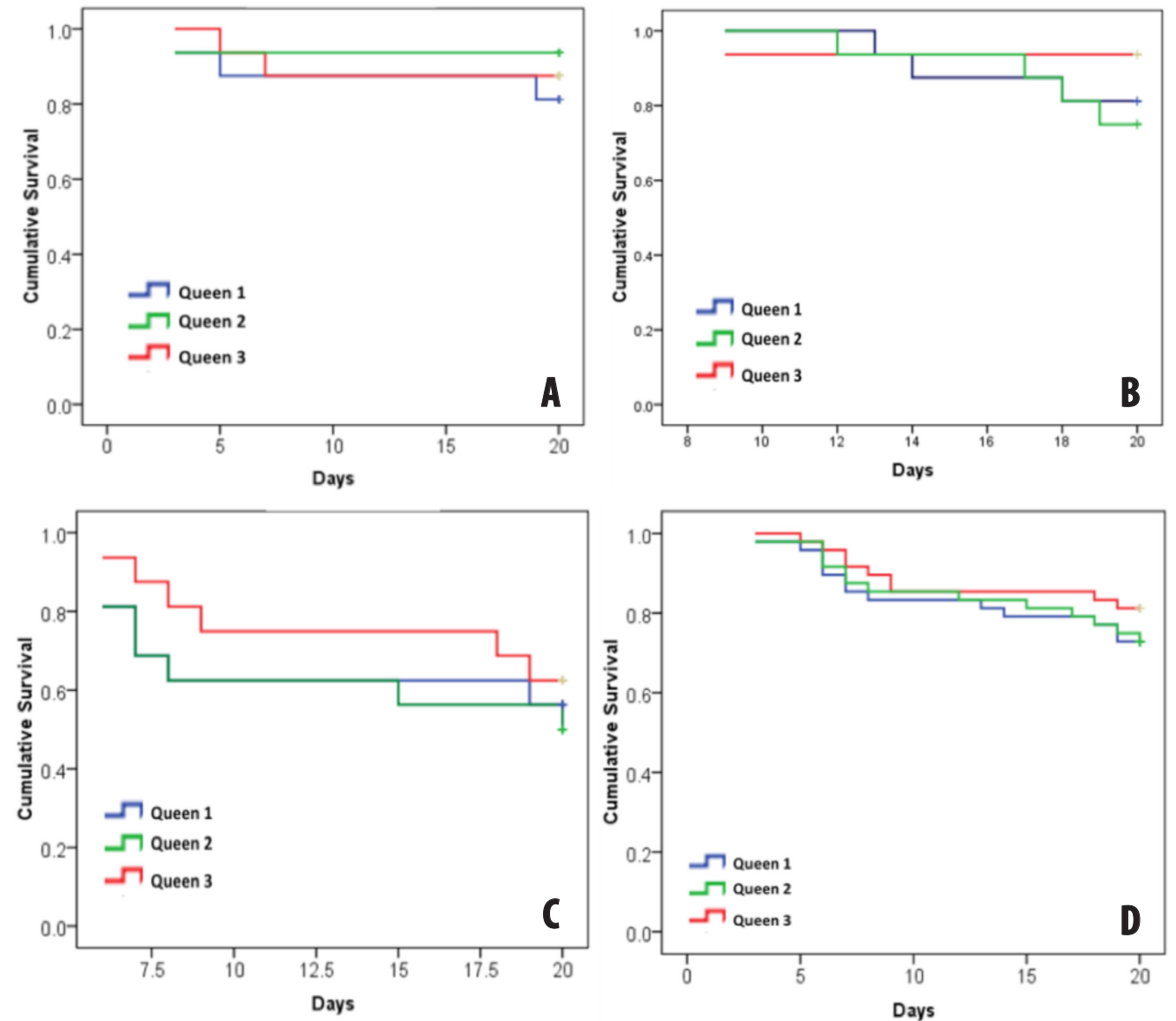

Fig. 3. Cumulative survival of larvae grafted from the three queens over 20 days. A, group A, 1-day-old larvae; B, group B, 3-day-old larvae; C, group C, 4-day-old larvae; D, results of all groups (i.e. results of 1-, 3-, and 4-day-old larvae).

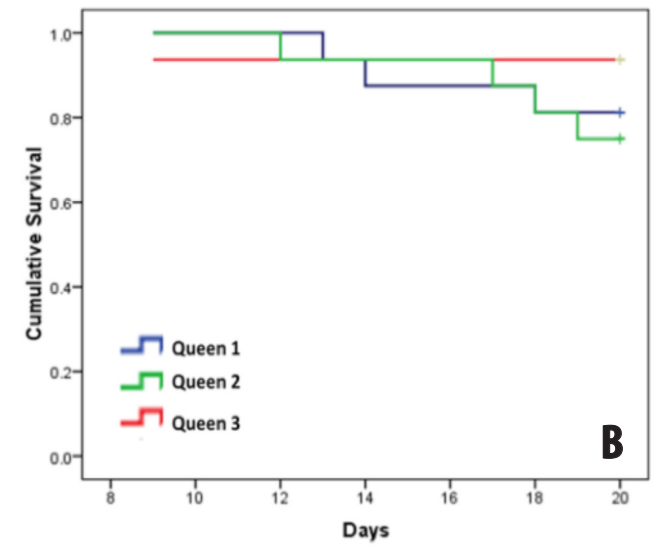

The effects of queens as a source of larvae on survival of each group and all groups combined are shown in Fig. 3. The survival of larvae obtained from the three Carniolan queens showed no significant differences for group A (Mantel-Cox 1.071, $p=0.585$ ), group B (Mantel-Cox 1.843, $p=0.398$ ), and group C (Mantel-Cox $0.657, p=0.72$ ). Also, no significant differences (Mantel-Cox 1.183, $p=0.553$ ) were found between the three queens for all groups (i.e. results of 1-, 3-, and 4-day-old larvae). Thus, larvae of each group exhibited similar survival rates regardless of queens. The ESM was $17.93 \pm 1.32,18.93 \pm 1.02$, and $18.25 \pm 1.16$ days for queen 1,2 , and 3 , respectively, for group A. The ESM was $19.06 \pm 0.54,19.12 \pm 0.50$, and $19.31 \pm 0.66$ days for queen 1,2 , and 3 , respectively, for group B. The ESM was $14.93 \pm 1.60,14.68 \pm 1.69$, and $16.68 \pm 1.34$ days for queen 1, 2, and 3, respectively, for group C. The ESM was $17.31 \pm 0.75,17.58 \pm 0.74$, and $18.08 \pm 0.65$ days for queen 1,2 , and 3, respectively for all groups. It is clear that ESM of larvae from the three queens within each group was very similar. It is also obvious that larval age at grafting is the main reason behind survival differences, while queen as a source of larvae had insignificant effect, especially as they represented the same subspecies.

Consequently, apart from well-known effects of rearing 
environment (e.g., temeprature, relative humidity, sterility etc.; Crailsheim et al. 2013) and feeding protocol (Aupinel et al. 2005), survival of larvae under laboratory conditions can be significantly affected by larval age at grafting.

\section{Conclusions}

Testing of xenobiotics on developmental stages of honey bee is still a challenge for scientists. Using the OECD model of grafting first instar larvae, which have potentially higher mortality during bioassay can be overcome by use of 3-dayold larvae, mainly in the case when the aim of the bioassay is to study harmful effect of xenobiotics on larval or pupal stage after single exposure. Our results indicate that using larvae at this particular age, which at the beginning of the experiment demonstrated lower mortality in comparison to 1-day-old larvae is the best option (practical and economical). Also, larvae at this age showed better survival until hatching of adults, compared with 1- and 4-day-old larvae.

\section{References}

Abou-Shaara H.F. 2014. The foraging behaviour of honey bees, Apis mellifera: a review. Vet. Med. 59: 1-10.

Abou-Shaara H.F., Owayss A.A., Ibrahim Y.Y., Basuny N.K.. 2017. A review of impacts of temperature and relative humidity on various activities of honey bees. Insect Soc. 64: 455-463.

Aupinel P., Fortini D., Dufour H., Tasei J., Michaud B., Odoux J., Pham-Delegue M. 2005. Improvement of artificial feeding in a standard in vitro method for rearing Apis mellifera larvae. Bull. Insectol. 58: 107-111.

Balayiannis G., Balayiannis P.2008. Bee honey as an environmental bioindicator of pesticides' occurrence in six agricultural areas of Greece. Arch. Environ. Contam. Toxicol. 55: 462-470.

Conti M.E., Botrè F. 2001. Honey bees and their products as potential bioindicators of heavy metals contamination. Environ. Monit. Assess. 69: 267-282.

Crailsheim K., Brodschneider R., Aupinel P., Behrens D., Genersch E., Vollmann J., Riessberger-Gallé U. 2013. Standard methods for artificial rearing of Apis mellifera larvae. J. Apic. Res. 52: $1-16$.

Elekonich M.M., Roberts S.P. 2005. Honey bees as a model for understanding mechanisms of life history ztransitions. Comp. Biochem. Physiol. A Mol. Integr. Physiol. 141: 362-371.

Johnson R.M. 2015. Honey bee toxicology. Annu. Rev. Entomol. 60: 415-434

Ken T., Bock F., Fuchs S., Streit S., Brockmann A., Tautz J. 2005. Effects of brood temperature on honey bee Apis mellifera wing morphology. Acta Zool. Sin. 51: 768-771.

Mullin C.A., Frazier M., Frazier J.L., Ashcraft S., Simonds R., van Engelsdorp D., Pettis, J.S. 2010. High levels of miticides and agrochemicals in North American apiaries: Implications for honey bee health. PLoS One 5: e9754.

OECD 2013. Guideline for the testing of chemicals No. 237: Honey bees (Apis mellifera) larval toxicity test, single exposure, section 2: effects on biotic systems. 10.1787/9789264203723en.

OECD 2016. Guidance document on honey bee larval toxicity test following repeated exposure. Published Jul 15, 2016. ENV/JM/ MONO(2016)34.

Tautz, J. Maier S., Groh C., Roessler W., Brockmann A. 2003. Behavioral performance in adult honey bees is influenced by the temperature experienced during their pupal development. Proc. Natl. Acad. Sci. USA 100: 7343-7347.

Visscher, P. K., Crailsheim, K., Sherman, G. 1996. How do honey bees (Apis mellifera) fuel their water foraging flights?. J. Insect Physiol. 42: 1089-1094.

Zhelyazkova I. 2012. Honey bees - bioindicators for environmental quality. Bulg. J. Agric. Sci. 18: 435-442.. 